\title{
Failure is not an option
}

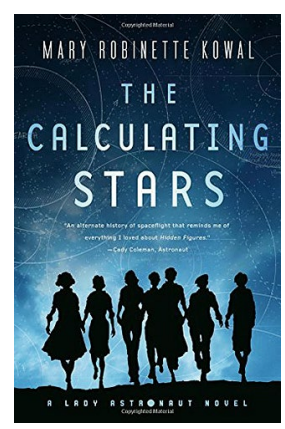

\author{
The Calculating \\ Stars: A Lady \\ Astronaut Novel \\ By Mary Robinette \\ Kowal
}

TOR BOOKS: 2018. 342pp. $€ 8.99$

। is 1952 , and a meteorite has just slammed into the eastern seaboard of the United States, destroying Washington DC and triggering an extinction-level climate catastrophe. Humanity has one choice if it hopes to survive: to move outwards to the stars.

This premise motivates the alternative history of The Calculating Stars: A Lady Astronaut Novel by Mary Robinette Kowal, which in August won the 2019 Hugo Award for Best Novel. This win cemented the novel's earlier successes since its publication last summer, having won the Nebula Award for Best Novel and the Locus Award for Best Science Fiction Novel, a rare sweep of three of the top awards in science fiction.

The Calculating Stars takes us to an alternative timeline where humanity must focus on space travel far before our own space race between the USSR and the US in the 1960s. The meteorite impact has triggered brutal shifts in global climate, leading to the collapse of the Soviet Union and to an international effort to reach beyond the bounds of Earth for the survival of humanity. Our protagonist is Elma York, a World War II pilot and brilliant mathematician with a doctorate in physics who must face the prejudice of the time in order to attain her dreams of space.

Elma and her rocket scientist husband Nathanial barely survive the initial impact of the meteorite, and as the world comes to realize that the impact will inevitably lead to a deadly global temperature rise, they both move forward into integral roles in the International Aerospace Coalition (IAC), a scientific organization founded to make sure humanity can spread to the stars. Elma works initially as one of the 'computers' running the complex calculations that underpin the entire endeavour, but her frustration grows as she sees the establishment unwilling to take the necessary steps to truly move humanity beyond this world. In particular if there are to be colonies, women must go to space, not only gung-ho male test pilots. Elma must push against prejudice and misogyny to earn her place as an astronaut, fighting every inch against the ingrained expectations of those around her.

This world is intriguingly presented. The removal of the Soviet Union as an existential threat and the relatively harmonious unification of the world behind the endeavour of spreading humanity to the Moon, Mars and beyond allow the novel to focus on the internal battles against entrenched gender and racial inequality that Elma faces and encounters. Whilst there are murmurs of the militarization of the space programme and opposition from crazed fundamentalists and politicians unconvinced by the threat of the global warming, overall these are minor events to be brushed aside. The real threat here is that the IAC may fail altogether if it refuses to make use of all of its resources, namely the brilliant and driven cadre of women in its ranks. The world is presented as nostalgic Americana with cocktails at dinner and polite smiles all around, even as hints of the growing climate catastrophe are drip-fed into the background and the deep wells of sexism and racism fester. The world and its inhabitants are traumatized by the meteorite, and its lasting legacy trickles through the novel in the smallest of moments.

Elma is a fantastic pilot and brilliant mathematician, but she battles with anxiety and this is utterly integral to the narrative. Public speaking is a nightmare for her, and the approach of a reporter with a cameraman is enough to make her queasy. As she fights for the right of women to help save the world she finds herself as the face of a movement as the 'Lady Astronaut' and must resolve to help not only herself, but every girl out there who dreams of the stars. At every step the stigma of mental health issues presses on her.

But even as she rails against the smothering patriarchy above, Elma herself has a degree of privilege as a white woman and the wife of the lead engineer at the IAC and that allows her leeway where others have none. As she confronts those with prejudice against her, she must also confront her own prejudices and come to terms with them.

Kowal wonderfully crafts a narrative where the antagonist is systemized sexism and racism, and whilst those issues might have avatars such as charming poster boy for the space programme Stetson Parker, the world presented in The Calculating Stars is earnest and optimistic in its belief that skill and grit can push against those beliefs. The importance of family and community (be that husband or brother or friend or flying club) underlies the achievements of Elma. Her community of computers and pilots, brilliant women from all backgrounds, drive her on even at her lowest moments.

The alternative timeline presented by Kowal shows us a world where the space race is a unifying movement, humanity with all its flaws racing against annihilation rather than racing for dominance over one another. The domesticity presented throughout the novel is a constant reminder of what the IAC and its astronauts are striving to save. In the face of catastrophe and gender and racial inequality, these women - scientists and computers and pilots - push forward. It is their dogged determination, which typifies this version of the 1950s, that warrants the nostalgia.

Reviewed by lan Green

Senior Editor, Nature Communications.

e-mail:ian.green@nature.com

Published online: 1 October 2019

https://oi.org/10.1038/s41567-019-0676-4 